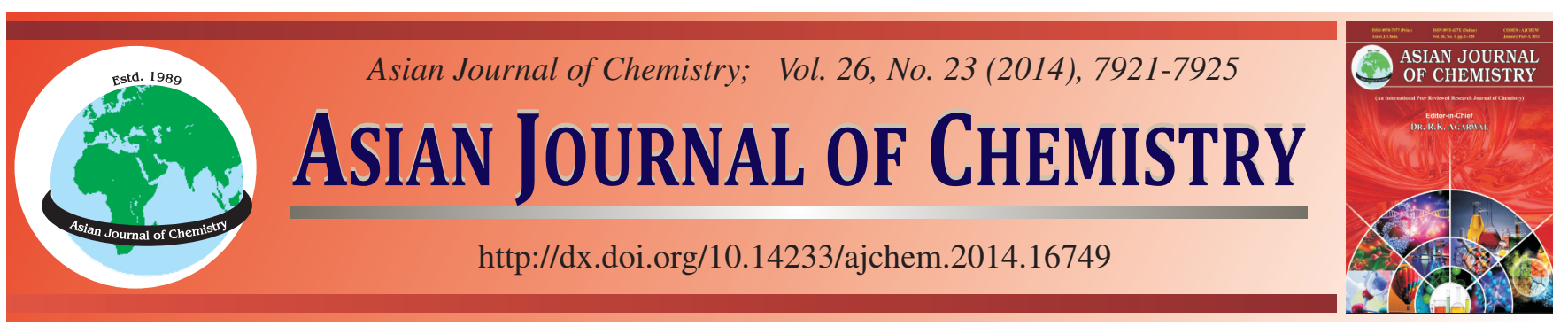

\title{
Immobilization of Xylanase Xyn II-ST4 and -ST5 with Biotinylated Poly(lactic-co-glycolic Acid) Nanosphere Carrier Increased Their Thermal and pH Stabilities
}

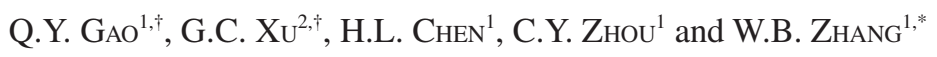

${ }^{1}$ School of Life Science and Technology, Xinxiang Medical University, Xinxiang, Henan Province, P.R. China

${ }^{2}$ School of Public Health, Xinxiang Medical University, Xinxiang, Henan Province, P.R. China

$\dagger$ These authors contributed equally to this work.

*Corresponding author: Fax: +86 373 3831859; Tel: +86 373 3831928; E-mail: zhangwenbo@xxmu.edu.cn

Received: 25 November 2013;

Accepted: 13 March 2014;

Published online: 15 November 2014;

AJC-16264

Xyn II-ST4 and -ST5 are recombinant enzymes derived from Xyn II, a xylanase from Aspergillus niger prepared by replacing the serine and/or the threonine with arginine at its serine/threonine surface residues. Xyn II-ST4 and -ST5 were immobilized with poly(lactic-coglycolic acid) based nanosphere carrier and crosslinked by glutaraldehyde to improve their thermal and pH stabilities. Single factor analyses, orthogonal experiments and variance analyses were conducted to determine the significant factors for immobilization. Results showed that the recovery of enzymatic activities of immobilized Xyn II-ST4 and -ST5 were 79.68 and $81.23 \%$, respectively. In addition, the optimum temperature for ST4 and ST5 was increased by 5 and $3{ }^{\circ} \mathrm{C}$, respectively and the optimum pH varied from 4.5 to 5 . Results suggested that the poly(lactic-co-glycolic acid) nanosphere is a potential carrier for the immobilization of Xyn II-ST4 and -ST5 because the poly(lactic-co-glycolic acid) nanosphere can improve their thermal and $\mathrm{pH}$ stabilities.

Keywords: Glutaraldehyde, Immobilized enzyme, Nanosphere, Poly(lactic-co-glycolic acid), Xylanase.

\section{INTRODUCTION}

Xylanase is an important glycoside hydrolase that is widely applied in industry and agriculture. Xylanase, which is ubiquitously found in several organisms, such as bacteria, marine algae, molds, yeasts, terrestrial plants, crustaceans and other invertebrates, can degrade xylan into xylo-oligosaccharides or xyloses by endo- or exo-mode of action ${ }^{1-3}$. However, the applications of free xylanase are limited because of its poor stability, low half-life and high cost. Thus, directed mutagenesis methodology was used for selecting optimized mutant enzymes to improve the stability of xylanase $e^{4-7}$. The stability of xylanase can be further improved by enzyme immobilization, in which free enzyme molecules are entrapped into a carrier or a matrix to maintain or improve its natural activity. Immobilized enzymes (IEs) outperform free enzymes in terms of stability, which facilitate immobilized enzymes to separate from their liquid phase for recycling ${ }^{8,9}$. The carrier significantly influences the stability of the enzyme and the accessibility of the substrate. Therefore, several factors, such as particle size, pore size, inner structure, functional group density, spacer, backbone and properties of functional groups of matrix, should be considered in choosing the carrier ${ }^{10}$. Nanomaterial carrier is advantageous over conventional matrix, particularly in nonaqueous systems and for larger substrates $^{11-14}$

Material and nanofabrication methods significantly influence the surface property of the nanomaterial, which in turn significantly influences the bioactivity and the stability of immobilized enzyme. Poly(lactic-co-glycolic acid) (PLGA) and chitosan, which possesses certain special properties such as having a large surface area to volume ratio, were extensively used in enzyme immobilization as nanomatrices ${ }^{15}$. In these nanomatrices, chitosan and/or its derivatives were widely selected as poly(lactic-co-glycolic acid) surface modifier ${ }^{16-18}$.

A biotinylated chitosan derivative (Bio-CS) modified poly(lactic-co-glycolic acid) nanosphere (Bio-CS-PLGA) was synthesized (Fig. 1). Biotinylated chitosan derivative modified poly(lactic-co-glycolic acid) was structurally characterized using a scanning electronic microscope (SEM) and a nuclear magnetic resonance (NMR) spectrometer ${ }^{19,20}$. Mutant enzymes Xyn II-ST4 and -ST5 were prepared by replacing the Ser and/ or the Thr residues with four (ST4) or five arginines (ST5) on the Ser/Thr surface of the enzyme ${ }^{21}$. Biotinylated chitosan derivative modified poly(lactic-co-glycolic acid) nanomaterial was prepared as carrier matrix using glutaraldehyde as crosslinking reagent to improve the stability of immobilized Xyn II-ST4 and -ST5. Several factors that influence the optimum 


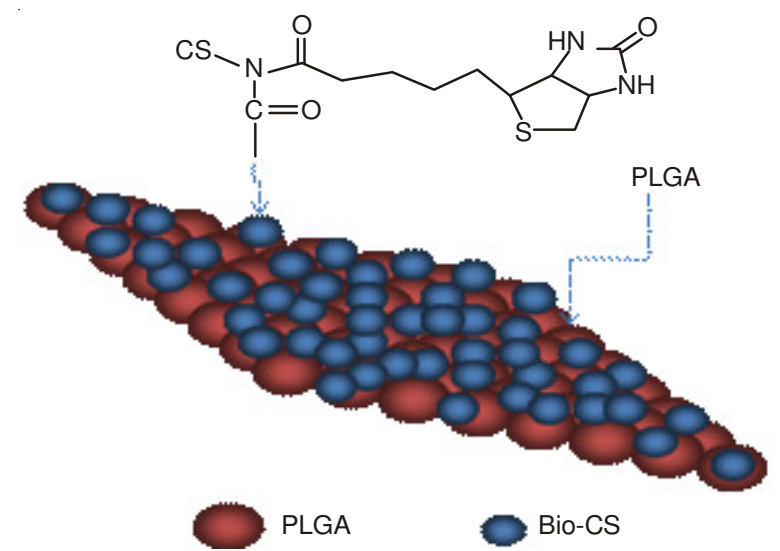

Fig. 1. Structure of biotinylated chitosan derivative poly(lactic-co-glycolic acid)

temperature, the optimum $\mathrm{pH}$, the thermal stability and the $\mathrm{pH}$-stability of free enzymes and immobilized enzymes were investigated.

\section{EXPERIMENTAL}

Chitosan (low molecular weight; degree of deacetylation: $85 \%$ ) was purchased from Sigma Aldrich Inc. Biotin was purchased from Beijing Jiakangyuan Science \& Technology Co., Ltd. Strain of Pichia pastoris was preserved at Henan Key Laboratory of Hereditary Disease and Molecular Targeted Therapy (Cultivating Base). Other reagents were mainly analytical reagents.

Preparation and characterization of biotinylated chitosan derivative modified poly(lactic-co-glycolic acid): Biotinylated chitosan derivative modified poly(lactic- $\mathrm{co}$-glycolic acid) nanospheres were prepared according to reference ${ }^{19}$. The structural features were characterized using SEM (JEOL, JSM6700F, Japan), particle size and zeta potential analyzer (ZetaPALS Brookhaven Instruments Co., US) and NMR spectrometer (INOAVA $500 \mathrm{MHz}$ Varian, US).

Purification of Xyn II-ST4 and ST5: Mutant enzyme Xyn II-ST4 and -ST5 were expressed in Pichia pastoris. The supernatant from the yeast fermentation broth was treated by ultrafiltration, salted out by $\left(\mathrm{NH}_{4}\right)_{2} \mathrm{SO}_{4}$, desalted by dialysis and then concentrated with polyethylene glycol 20000. Finally, the crude enzyme liquid was further purified using Sephadex G-50 column chromatography to harvest the pure target protein.

Standard curve for D-xylose assay: Different concentrations (i.e., 0, 0.5, 1.0, 1.5, 2.0 and $2.5 \mathrm{~mL}$ ) of D-xylose standard liquid $(0.2 \mathrm{mg} / \mathrm{mL})$ were individually measured and transferred into $25 \mathrm{~mL}$ test tubes with ground-in glass stopper. A total of $2.5 \mathrm{~mL}$ of distilled water was added into each tube. Then, $2.5 \mathrm{~mL}$ dinitrosalicylic acid solution was added to each tube, which was then shaken with a vortex mixer. Each tube was developed for coloration in water bath for $10 \mathrm{~min}$, dropped in cool water, added with $5 \mathrm{~mL}$ of distilled water and mixed with a vortex mixer. Finally, the tube with $0 \mathrm{mg} / \mathrm{mL}$ of xylose was set as blank and the absorbance at $540 \mathrm{~nm}$ was determined. Based on this protocol, the regression equation was deduced as the following formula:

$$
y=1.2429 x-0.0543, R^{2}=0.9918
$$

Assay method of enzyme activities: Xylanase activities were determined by dinitrosalicylic acid method ${ }^{21}$. The enzyme activity of xylanase was defined under the following reaction condition: $50^{\circ} \mathrm{C}, \mathrm{pH} 4.6$, reaction time of $1 \mathrm{~min}, 1 \mathrm{IU}$ xylanase or immobilized xylanase to determine the relative activity of immobilized enzyme.

Recovery of immobilized enzyme activity $=$ (activity of immobilized enzyme $\div$ activity of free enzyme for immobilization) $\times 100 \%$.

Immobilization of Xyn II-ST4 and ST5: $30 \mathrm{mg}$ Biotinylated chitosan derivative modified poly(lactic-co-glycolic acid) nanospheres were measured and added to $1 \mathrm{~mL}$ of tris- $\mathrm{HCl}$ buffer solution ( $\mathrm{pH} 7.6 ; 0.05 \mathrm{~mol} / \mathrm{L})$. Then, the solution was treated and stirred with ultrasonication for $10 \mathrm{~min}$. A total of 2 $\mathrm{mL}$ of purified enzyme solution (enzyme activity: $30000 \mathrm{IU} /$ g) was added to the biotinylated chitosan derivative modified poly(lactic-co-glycolic acid) solution, which was then treated with ultrasonication for $0.5 \mathrm{~h}$ and crosslinked with $4 \%$ (w/v) glutaraldehyde for $2.5 \mathrm{~h}$ to prepare immobilized enzyme. Immobilized enzyme was fixed for $4 \mathrm{~h}$ under $4{ }^{\circ} \mathrm{C}$. Then, the supernatant was decanted after centrifugation and the pellet was washed with tris-HCl buffer three times. Immobilized xylanses, which were denoted as Xyn II-ST4'and -ST5' were leached, harvested and stored at $4{ }^{\circ} \mathrm{C}$.

Data analysis with orthogonal experimental design: First, the factors influencing immobilized enzymes activities, such as the mass fraction of the nanospheres, the volume fraction of glutaraldehyde and the crosslinking time, were determined using single-factor analysis. Then, the abovementioned three factors were chosen and each factor took three levels to perform $\mathrm{L}_{9}\left(3^{3}\right)$ orthogonal tests (Table-1).

\begin{tabular}{cccc}
\multicolumn{4}{c}{ TABLE-1 } \\
\hline \multirow{3}{*}{ Levels } & \multicolumn{3}{c}{ Factors } \\
\cline { 2 - 4 } & Bio-CS-PLGA (A)/mg & Glutaral (B) \% & $\begin{array}{c}\text { Crosslinking } \\
\text { time (C)/h }\end{array}$ \\
\hline 1 & 25 & 3 & 2.0 \\
2 & 30 & 4 & 2.5 \\
3 & 35 & 5 & 3.0 \\
\hline
\end{tabular}

\section{RESULTS AND DISCUSSION}

SEM analysis for biotinylated chitosan derivative modified poly(lactic-co-glycolic acid) nanosphere: Biotinylated chitosan derivative modified poly(lactic- $\mathrm{co}$-glycolic acid) biomaterial was subjected to SEM analysis (Fig. 2). Results showed that unmodified poly(lactic-co-glycolic acid) nanospheres were spherical and structurally uniform and that poly(lactic-co-glycolic acid) was seldom bound to biotinylated chitosan derivative. Moreover, biotinylated chitosan derivative modified poly(lactic-co-glycolic acid) was spherical as well. However, biotinylated chitosan derivative was closely bound to poly(lactic-co-glycolic acid), suggesting that biotinylated chitosan derivative was conjugated with poly(lactic-co-glycolic acid).

Expression and purification of mutant enzyme: SDSPAGE results showed that the mutant enzyme was expressed in Pichia pastoris (Fig. 3). The molecular mass of the mutant 

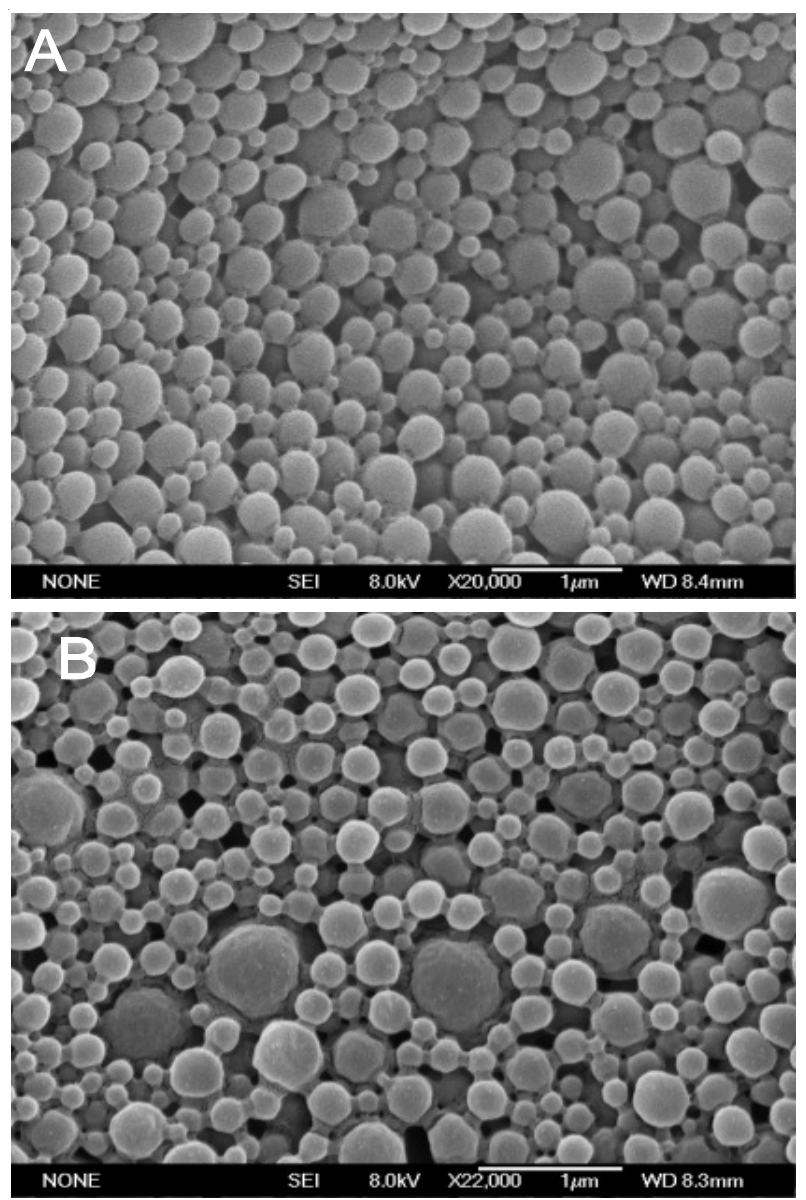

Fig. 2 Scanning electron microscopy of nanospheres (A: poly(lactic-coglycolic acid) nanospheres, B: biotinylated chitosan derivative modified poly(lactic-co-glycolic acid) nanospheres)

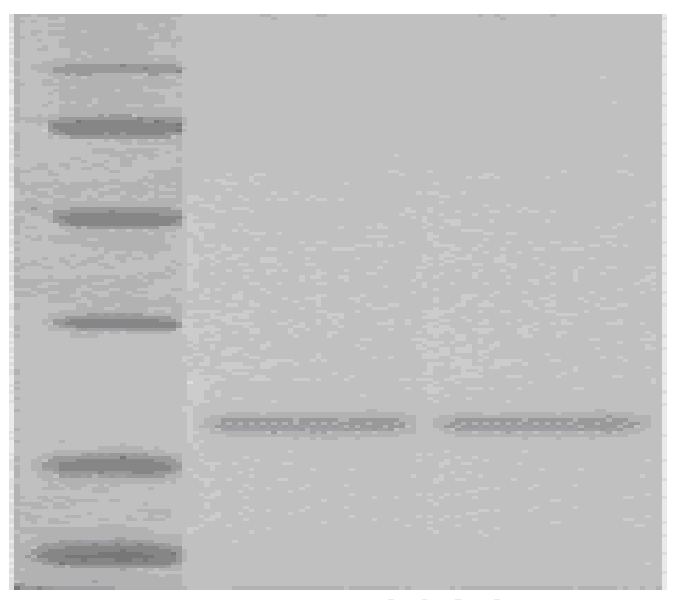

Fig. 3. SDS-PAGE analysis of ST4 and ST5 expressed in Pichia pastoris (Lanes are shown from left to right: M-Low-molecular-weight marker, ST4 and ST5)

enzymes Xyn II-ST4 and -ST5 was both $23.3 \mathrm{kD}$, which is consistent with literature, suggesting that Xyn II-ST4 and -ST5 were expressed and purified.

Single-factor analysis: Single factor analysis was applied by investigating the effect of a certain factor that could influence the enzyme activities while keeping the other factors unchanged to determine which factors affect the enzyme activities.
Effect of mass fraction of nanospheres on activities of immobilized enzyme: The surface-to-volume ratio of carriers influences the activities of immobilized enzyme because its concentration influences the accessibility of the substrate to immobilized enzyme. Results showed that the mass fraction of nanospheres influenced the activities of the Xyn II-ST4' and -ST5' (Fig. 4). When the mass fraction was greater than $30 \mathrm{mg}$, the relative immobilized enzyme activities decreased. As the mass fraction of the nanospheres increased, the particle became more rigid and the specific surface area became smaller. Therefore, the accessibility of the xylanase to the carrier was influenced by the mass fraction of the nanospheres.

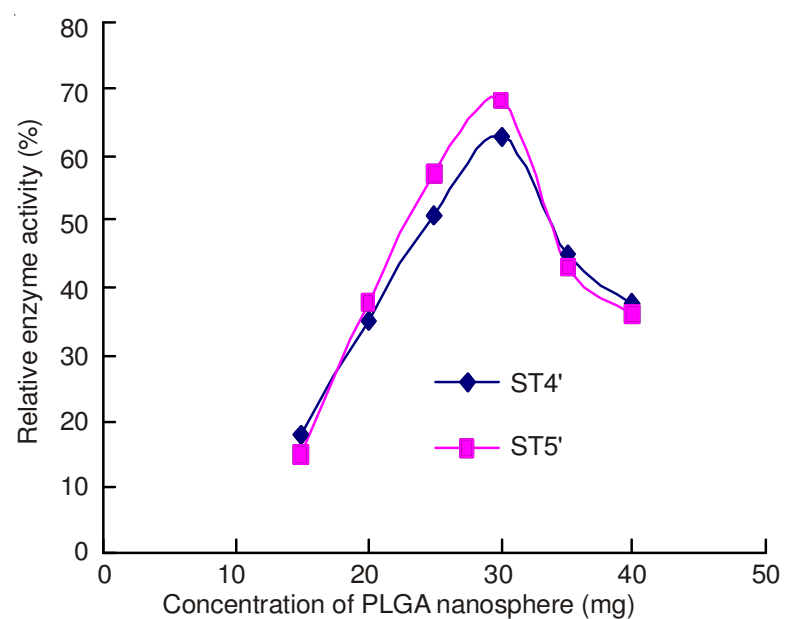

Fig. 4. Effects of biotinylated chitosan derivative poly(lactic-co-glycolic acid) nanosphere on the activity recovery of immobilized enzyme

Effect of glutaraldehyde concentration: The concentration of glutaraldehyde is very important for immobilization. Results showed that the activities of Xyn II-ST4' and -ST5' varied with glutaraldehyde concentration (Fig. 5). Less xylanase would be bound to carriers because of lower degrees of crosslinking resulting from a lesser density of glutaraldehyde. Meanwhile, a higher degree of crosslinking for protein modification would possibly constraint its structure, which could compromise its activities. Consequently, the optimized concentration of glutaraldehyde is $4 \%$.

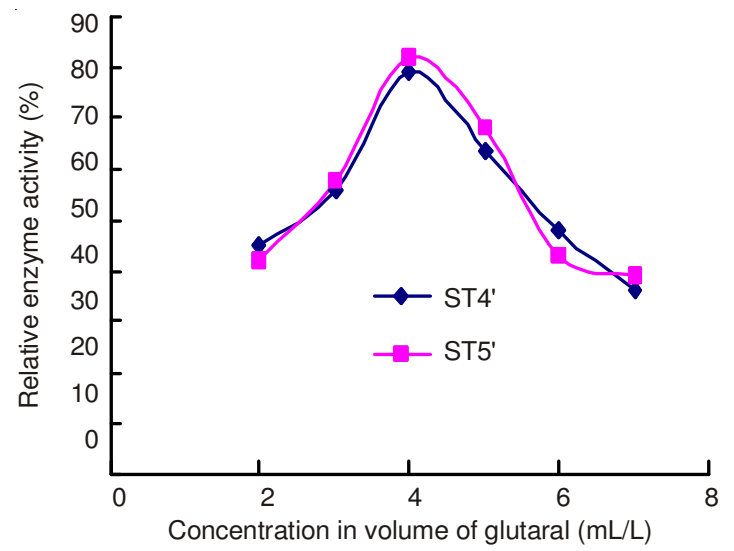

Fig. 5. Immobilization of xylanase at different glutaraldehyde concentrations

Effect of crosslinking time to activities of immobilized enzyme: The highest activity recovery of immobilized enzyme 
was obtained at $2.5 \mathrm{~h}$ during crosslinking (Fig. 6). When the reaction time is shorter than $2.5 \mathrm{~h}$, the crosslinking between glutaraldehyde and protein was incomplete. The functional groups of the carriers were crosslinked by glutaraldehyde through Schiff reaction. Thus, the activities of immobilized enzymes increase as xylanase is added to the carriers. The influence of crosslinking time on the reaction is insignificant when the reaction time is longer than $2.5 \mathrm{~h}$ because of the exhaustion of the aldehyde group.

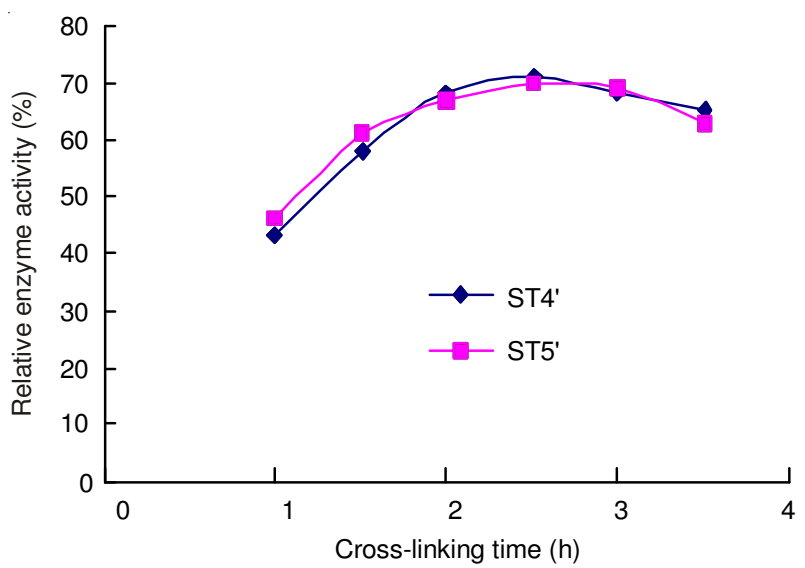

Fig. 6. Effects of the crosslinking time on the relative activity of immobilized enzyme

Optimization of xylanase immobilization using biotinylated chitosan derivative modified poly(lactic-coglycolic acid) nanomaterial as carrier: Results of the singlefactor analysis demonstrated that the mass fraction of nanospheres, the volume fraction of glutaraldehyde and the crosslinking time have similar effects on the activities of Xyn II-ST4' and -ST5'. Thus, an orthogonal analysis on Xyn IIST5' was designed to clarify which factor is the most significant in crosslinking reactions.

Range analysis suggested that the sequence of factors influencing immobilized enzyme activities is, in order of importance, $\mathrm{A}>\mathrm{B}>\mathrm{C}$ (Table-2). The optimized condition

\begin{tabular}{llllc}
\multicolumn{5}{c}{ TEST RESULTS OF ORTHOGONAL DESIGN } \\
\hline Level & A & B & C & Relative enzyme activity (\%) \\
\hline 1 & 1 & 1 & 1 & 81.74 \\
2 & 1 & 2 & 2 & 90.67 \\
3 & 1 & 3 & 3 & 87.23 \\
4 & 2 & 1 & 2 & 93.05 \\
5 & 2 & 2 & 3 & 82.32 \\
6 & 2 & 3 & 1 & 100.00 \\
7 & 3 & 1 & 3 & 80.66 \\
8 & 3 & 2 & 1 & 71.38 \\
9 & 3 & 3 & 2 & 78.14 \\
K1 & 259.64 & 255.45 & 253.12 & \\
K2 & 275.37 & 244.37 & 261.86 & \\
K3 & 230.18 & 265.37 & 250.21 & \\
k1 & 86.55 & 85.15 & 84.37 & \\
k2 & 87.53 & 81.46 & 87.29 & \\
k3 & 76.72 & 88.46 & 83.41 & \\
R & 45.19 & 21.00 & 11.65 & \\
\hline In Table 2, K1, K2, and K3 denote the sum of the relative enzymatic \\
activities of immobilized enzymes for each factor and each level. k1, \\
k2, and k3 represent the average relative enzymatic activity of \\
immobilized enzyme at each factor and each level
\end{tabular}

was $A_{2} B_{3} C_{2}$, that is, the mass fraction of nanospheres was 30 $\mathrm{mg}$, the volume fraction of glutaraldehyde was $5 \%$ and the crosslinking time was $2.5 \mathrm{~h}$. Under the optimized conditions, the recovery of enzymatic activities of Xyn II-ST4' and -ST5' was 79.68 and $81.23 \%$, respectively.

Variance analysis: Results showed that the mass fraction of nanospheres (A) had the most significant influence in this experiment $(\mathrm{p}<0.01)$. The volume fraction of glutaraldehyde (B) is a significant factor as well $(\mathrm{p}<0.05)$. However, crosslinking time $(\mathrm{C})$ presented no significant effect in this study (Table-3).

\begin{tabular}{llclll}
\multicolumn{5}{c}{ TABLE-3 } \\
RESULTS OF VARIANCE ANALYSIS \\
\hline $\begin{array}{l}\text { Variance } \\
\text { source }\end{array}$ & $\begin{array}{l}\text { Sum of } \\
\text { squares }\end{array}$ & $\begin{array}{c}\text { Degree of } \\
\text { freedom }\end{array}$ & $\begin{array}{c}\text { Mean } \\
\text { square }\end{array}$ & F value & Significance \\
\hline A & 71.47 & 2 & 35.74 & 113.92 & $* * *$ \\
B & 24.52 & 2 & 12.26 & 37.01 & $* *$ \\
C & 8.16 & 2 & 4.08 & 13.01 & \\
Test error & 5.696 & 2 & 2.848 & & \\
Total & 104.15 & 8 & & & \\
$* *$ Significant effect. *** Highly significant effect. $\mathrm{F}_{0.01}(2,2)=99.00$. \\
$\mathrm{F}_{0.05}(2,2)=19.00$
\end{tabular}

Optimum pH and pH stability of free and immobilized xylanase: The $\mathrm{pH}$ level influences the velocity of enzyme reaction by influencing the enzymatic structure and the substrate dissociation. The optimum $\mathrm{pH}$ of Xyn II-ST4 and -ST5 changed from 4.5 to 5 after immobilization, which is beneficial for industrial application (Fig. 7). In contrast to free enzymes, the activities of immobilized Xyn II-ST4 and -ST5 remained high (Fig. 8).

Optimum temperature and thermal stability of immobilized xylanase: Temperature is an important influencing factor on enzymatic reactions. Changes in temperature could cause inactivation for thermal denaturation, $\mathrm{pKa}$ and binding capacity of enzyme and substrate. Results showed that the optimum temperature of ST4' and ST5' were $55^{\circ} \mathrm{C}$ and $58^{\circ} \mathrm{C}$, respectively (Fig. 9). The optimum temperatures of ST5' and ST4' increased by 5 and $3{ }^{\circ} \mathrm{C}$, respectively, relative to the free enzymes. Thermal treatment experiments suggested that the thermal stability of immobilized enzyme significantly improved (Fig. 10).

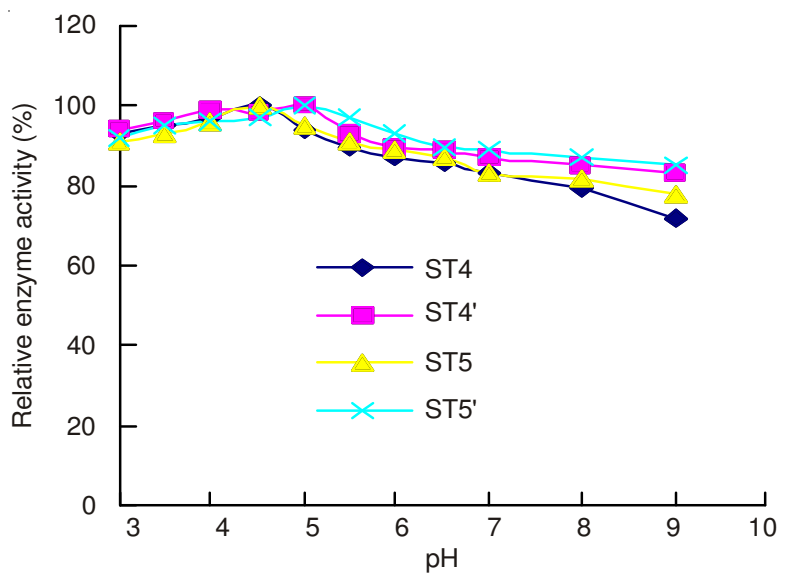

Fig. 7. Effect of $\mathrm{pH}$ on the relative activity of the free xylanase and immobilized enzyme 


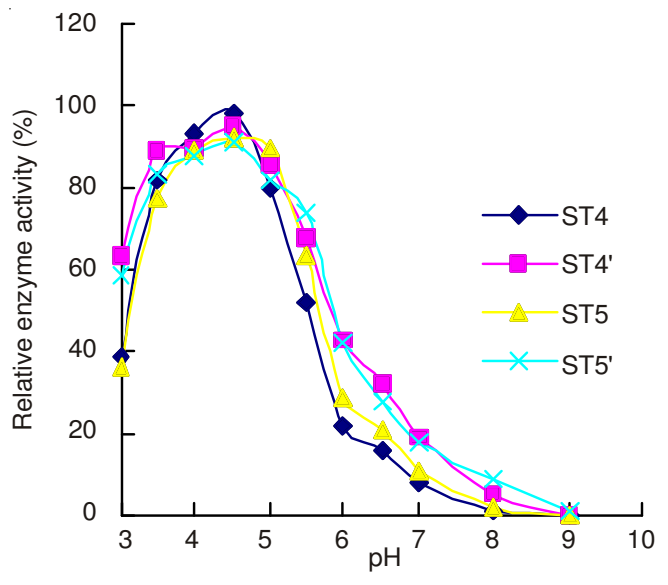

Fig. 8. Effect of pH on enzyme stability of free xylanase and immobilized enzyme

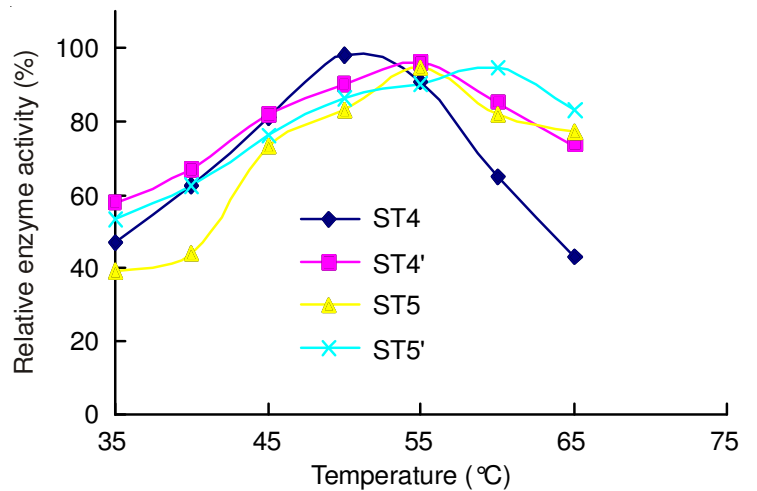

Fig. 9. Effect of temperature on the relative activity of free xylanase and immobilized enzyme

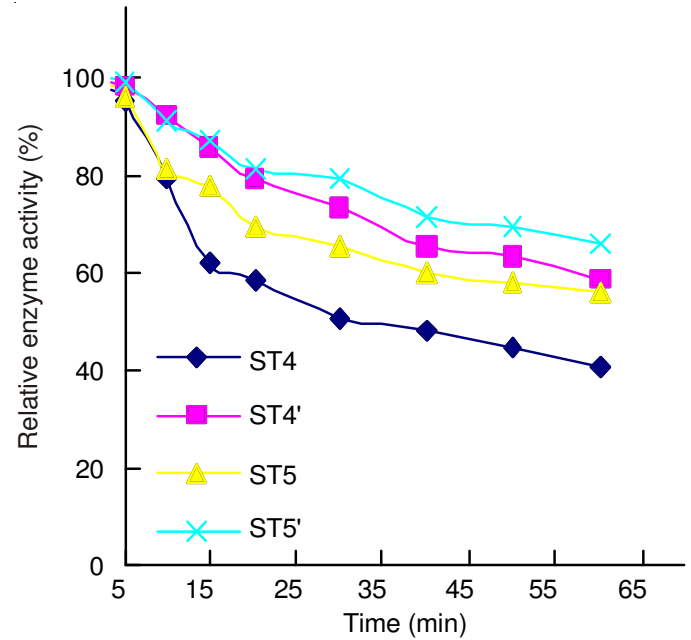

Fig. 10. Thermal stability of free xylanase and immobilized enzyme

\section{Conclusion}

In summary, mutant xylanase Xyn II-ST4 and -ST5 were immobilized with biotinylated chitosan derivative modified poly(lactic-co-glycolic acid) nanomaterial carrier using glutar- aldehyde as crosslinking reagent with high enzyme activity recovery. Optimized immobilization conditions were established using single factor analysis, orthogonal design and variance analysis. This work demonstrated that thermal and pH stabilities of xylanase can be improved by enzyme immobilization with nanomaterial carriers.

High operationally stable and biologically inert nanocarriers, such as mesoporous silica nanoparticles, were investigated to improve the thermal and $\mathrm{pH}$ stabilities of xylanase, which would be beneficial to xylanase industrial application.

\section{ACKNOWLEDGEMENTS}

This work was supported by the Natural Science Research Project of Henan Science and Technology Department (No. 2011A180026), the Key Science and Technology Research Program of Henan Science and Technology Department (No. 112102210299) and the Guide Project of Science and Technology Research of Henan Education Department (12B350006).

\section{REFERENCES}

1. S.A.I. Bokhari, F. Latif and M.I. Rajoka, World J. Microbiol. Biotechnol., 25, 493 (2009).

2. T. Collins, C. Gerday and G. Feller, FEMS Microbiol. Rev., 29, 3 (2005).

3. M.L. Polizeli, A.C. Rizzatti, R. Monti, H.F. Terenzi, J.A. Jorge and D.S. Amorim, Appl. Microbiol. Biotechnol., 67, 577 (2005).

4. Y. Nie, R. Xiao, Y. Xu and G.T. Montelione, Org Biomol Chem., 9, 4070 (2011).

5. W.L. Sung, K. Ishikawa and M. Yaguchi, United States Patent, 5866408 (1999).

6. H. Xiong, F. Fenel, M. Leisola and O. Turunen, Extremophiles, 8, 393 (2004).

7. H.M. Yang, B. Yao and K. Meng, Chin. J. Biotechnol., 22, 15 (2006).

8. A.M. Farag and M.A. Hassan, Enzyme Microb. Technol., 34, 85 (2004).

9. I. Hegedüs, J. Hancsók and E. Nagy, Appl. Biochem. Biotechnol., 168, 1372 (2012).

10. L. Huang and Z.M. Chen, Chin. J. Catal., 29, 57 (2008).

11. H. Jia, G. Zhu and P. Wang, Biotechnol. Bioeng., 84, 406 (2003).

12. P. Pandey, S.P. Singh, S.K. Arya, V. Gupta, M. Datta, S. Singh and B.D. Malhotra, Langmuir, 23, 3333 (2007).

13. N. Miletic, V. Abetz, K. Ebert and K. Loos, Macromol. Rapid Commun., 31, 71 (2010)

14. Z. Zhang, S. Huey Lee and S.S. Feng, Biomaterials, 28, 1889 (2007).

15. S.A. Ansari and Q. Husain, Biotechnol. Adv., 30, 512 (2012).

16. D.F.M. Neri, V.M. Balcão, R.S. Costa, I.C.A.P. Rocha, E.M.F.C. Ferreira, D.P.M. Torres, L.R.M. Rodrigues, L.B. Carvalho Jr. and J.A. Teixeira, Food Chem., 115, 92 (2009).

17. F. Huang, Z.G. Wang, L.S. Wan, X.J. Huang and Z.K. Xu, Chem. J. Chinese Univ., 31, 1060 (2010).

18. J.R. Chen, X. Ran and L. Wang, China Brewing, 7, 81 (2009).

19. H.L. Chen, H.B. Tang, W.Z. Yang, H. Chen, Y.S. Wang, L. Mei, T. Zhang, Q.Q. Xiong and Q.Q. Zhang, Chem. J. Chinese Univ., 31, 1682 (2010).

20. H. Chen, W. Yang, H. Chen, L. Liu, F. Gao, X. Yang, Q. Jiang, Q. Zhang and Y. Wang, Colloids Surf. B, 73, 212 (2009).

21. C.Y. Zhou, W. Wang and M.C. Wu, J. Northwest A\&F Univ. (Nat. Sci. Ed.), 38, 46 (2010). 